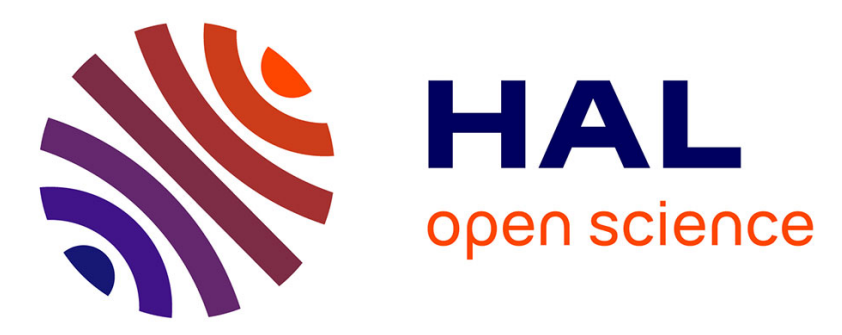

\title{
Experimental and numerical investigation of the weld repair of superplastic forming dies
}

Traian Branza, Arnaud Duchosal, Gilles Fras, Frédéric Deschaux-Beaume, Philippe Lours

\section{- To cite this version:}

Traian Branza, Arnaud Duchosal, Gilles Fras, Frédéric Deschaux-Beaume, Philippe Lours. Experimental and numerical investigation of the weld repair of superplastic forming dies. Journal of Materials Processing Technology, 2004, 155 (2, SI), pp.1673-1680. 10.1016/j.jmatprotec.2004.04.388 . hal-01716118

\section{HAL Id: hal-01716118 \\ https://hal.science/hal-01716118}

Submitted on 4 Dec 2019

HAL is a multi-disciplinary open access archive for the deposit and dissemination of scientific research documents, whether they are published or not. The documents may come from teaching and research institutions in France or abroad, or from public or private research centers.
L'archive ouverte pluridisciplinaire HAL, est destinée au dépôt et à la diffusion de documents scientifiques de niveau recherche, publiés ou non, émanant des établissements d'enseignement et de recherche français ou étrangers, des laboratoires publics ou privés. 


\title{
Experimental and numerical investigation of the weld repair of superplastic forming dies
}

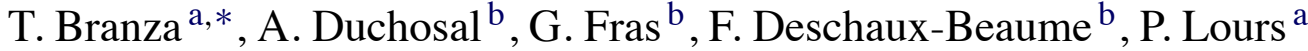

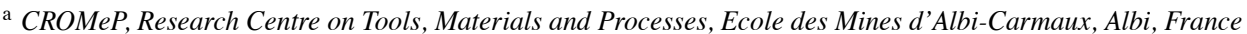 \\ ${ }^{\mathrm{b}}$ Laboratoire de Mécanique et Génie Civil, Université de Montpellier II, Nîmes, France
}

\begin{abstract}
Superplastic forming process (SPF) is an advanced process conducted at high temperature using moderate strain rates, typically used for shaping TA6V sheets for aerospace applications. Thermomechanical stresses on the forming dies due to successive forming cycles may result in the early degradation and even fracture of SPF tools through fatigue crack propagation. To reduce cost and extend service life, dies are generally weld-repaired and subsequently re-used in the typical severe conditions of SPF. The implementation of robust, easy processing welding techniques resulting in high quality repair able to sustain cumulative thermomechanical stresses is of utmost concern to SPF parts manufacturers. The paper focuses on the development of an automated TIG technique to weld repair high nickel, high chromium heat resistant alloys based on a complementary approach including thermal instrumentation, numerical simulation using Sysweld ${ }^{\mathrm{TM}}$ and metallurgical investigation; this former being performed on either as-received, repaired and repaired plus damaged materials.
\end{abstract}

Keywords: Welding; Numerical simulation; Superplastic forming; Dies

\section{Introduction}

Superplastic forming (SPF) consists in blowing sheets to shape, using argon pressure, within a die generally made of heat resistant cast steel. Process is conducted at high temperature, around $900{ }^{\circ} \mathrm{C}$ for TA6V, on materials showing fine grain microstructure. The sheet, while inflated by argon, gradually takes the shape dictated by the inner surface of the die. The elementary cycle of forming, including heating, isothermal exposure and cooling, is repeated as many times as necessary to complete the whole bench of parts to manufacture. Those cumulative cycles provoke the occurrence of very severe thermomechanical stresses within the heat resistant cast steel dies [1]. This may result in the initiation and propagation of fatigue cracks and ultimately to the early catastrophic rupture of the die.

The increasing demand for manufacturing costs reduction requires to seek adapted and reliable solutions for repairing, and thus extending the service life of the dies. Repairs are generally performed by TIG or welding with covered electrodes. However, processes used up to now do not show sufficient guarantees for the users. Indeed, repairing is carried

\footnotetext{
* Corresponding author.

E-mail addresses: branza@enstimac.fr (T. Branza), yelserval@yahoo.fr (A. Duchosal),deschaux@mail.iut-nimes.fr (F. Deschaux-Beaume), lours@enstimac.fr (P. Lours).
}

out in hostile industrial environment, which makes it difficult to perform properly. As a consequence, the mechanical performances of the welded joints, when exposed to the SPF thermomechanical cycles, are generally lower than those expected.

The paper focuses on the development of an automated TIG weld-repair technique for heat resistant cast steels typically used for manufacturing SPF dies. A double approach, including both thermal and mechanical numerical simulation and metallographic analysis, is developed in order to optimise welding process parameters.

\section{Materials and methodology}

The heat resistant cast steels used for the manufacturing of SPF dies generally show high contents of nickel and carbide-forming elements to ensure a good mechanical resistance at high temperature. They are also rich in chromium, promoting high oxidation resistance. According to the type of repair carried out, structural or cosmetic, the filler metal is either chemically homogeneous with the base metal or slightly different. The materials investigated in the present study are two austenitic alloys showing somewhat different composition and microstructure. One is richer than the other in nickel ( $50 \mathrm{wt} . \%$ versus $35 \mathrm{wt} . \%$ ) and carbon ( $0.46 \mathrm{wt} . \%$ versus $0.175 \mathrm{wt} . \%$ ) and both contains similar chromium (about 25\%). Weld repair tests are conducted us- 
ing Inconel 625 as filler metal. This material shows slightly different composition compared to both base metals, i.e. 65 wt.\% Ni, 22 wt.\% $\mathrm{Cr}$ and 0.014 wt.\% C.

The microstructure of austenitic heat resistant cast steel is invariably composed of a $\gamma$ matrix and primary eutectic MC carbides precipitated during solidification in the interdendritic spaces. Additional ageing treatment promotes the formation of secondary carbides in the shape of finely dispersed $\mathrm{M}_{23} \mathrm{C}_{6}$ particles within the austenitic matrix. Depending on composition and heat treatment, some difference may occur in the microstructure. Fig. 1a reveals the structure of the high carbon material showing coarse network of primary carbides and relatively small dendrite size. Conversely, the low carbon material exhibits finer precipitation of eutectic carbides and somewhat greater dendrite size (Fig. 1b). The morphology of highly facetted secondary $\mathrm{M}_{23} \mathrm{C}_{6}$ carbides

(a)

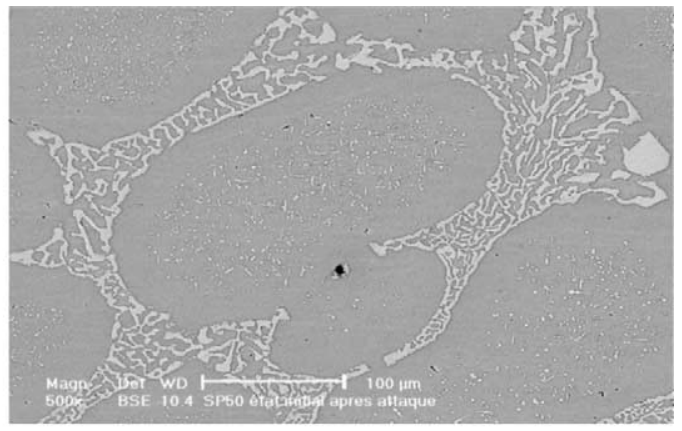

(b)

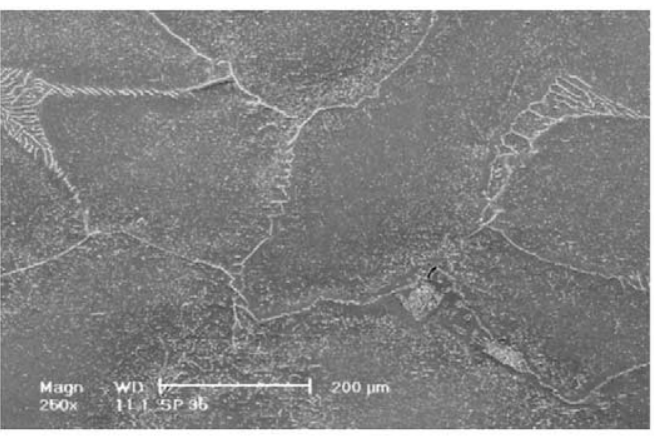

(c)

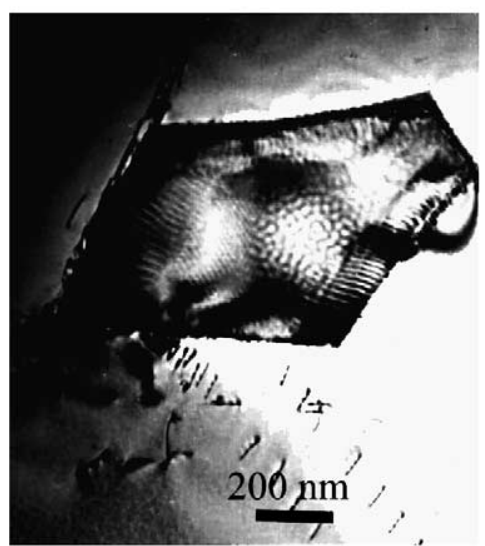

Fig. 1. SEM micrographs showing the structure of the high carbon alloy (a) and low carbon alloy (b) and TEM micrograph of a $\mathrm{M}_{23} \mathrm{C}_{6}$ secondary carbide precipitated in both alloys (c) $[\mathrm{M}=\mathrm{Cr}, \mathrm{W}$ or $\mathrm{Nb}]$. is seen on the TEM micrograph in Fig. 1c. This secondary precipitation ensures high thermal stability and mechanical performances to the material. For both materials, the metals $\mathrm{M}$ involved in the formation of carbides is $\mathrm{Cr}$. In addition, depending on the preferred alloying elements, $\mathrm{W}$ (high $\mathrm{C}$ alloy) or $\mathrm{Nb}$ (low $\mathrm{C}$ alloy) may combine to carbon to form carbides. Note the occurrence of a carbide-depleted zone along the interdendritic spaces, wider in the case of the carbon rich alloy.

To approach as much as possible the industrial case, plates as thick as $60 \mathrm{~mm}$, where a $\mathrm{V}$-shaped chamfer (with a radius of curvature at the bottom equals to $5 \mathrm{~mm}$ ) is machined, were weld-repaired by filling the entire groove with up to 47 passes. In order to analyse the influence of the plate thickness on both the feasibility of repairing and the possible occurrence of residual stresses within the metal and the concomitant stress induced plate deformation or crack initiation and propagation, several plates, ranging from 18 to $60 \mathrm{~mm}$ thick, were investigated. Of course, the shape and the depth of the machined chamfer to be filled is function of the plate thickness. For the thinnest plates (respectively the thickest), the chamfer is 5-7 $\mathrm{mm}$ (respectively $20 \mathrm{~mm}$ ) deep and exhibits an angle of $90^{\circ}$ (respectively $60^{\circ}$ ). The smallest grooves were filled using three passes. A systematic control of the weld beads is performed following each weld run in order to check for welding quality and reproducibility. This control is carried out using simple visual inspection, optical microscopy and non-destructive testing such as liquid penetrant inspection and/or X-ray radiography. In addition, a numerical approach using Sysweld ${ }^{\circledR}$ software is developed to help for the optimisation of the weld process parameters. This former will be further detailed in Section 4.

In order to further enhance the quality of weld, TIG process is automated to obtain regular deposit rates close to those used in practice. The microstructural investigations, including analyses by scanning electron microscopy (SEM), energy dispersive spectrometry (EDS) and microhardness measurements, are conducted both on industrial dies after degradation resulting from intensive use in real manufacturing environment and on weld joints deposited using the automated TIG equipment developed in the frame of the project.

\section{Results}

\subsection{Introduction: damage of weld-repaired industrial dies}

The thermomechanical stresses generated by the SPF process result in die damages which generally initiate on geometrical imperfections that can be either internal (foundry defects) or external (surface defects) to the die. Cracks can also propagate from zones, imperfectly designed and drawn, where high salient angle concentrates stresses for instance (Fig. 2a). Cracks due to cumulative thermal cycles are repaired and subsequently subject to the typical SPF thermal and mechanical constraints. In turn, those weld-repaired zones can crack upon thermomechanical cycling. Propaga- 

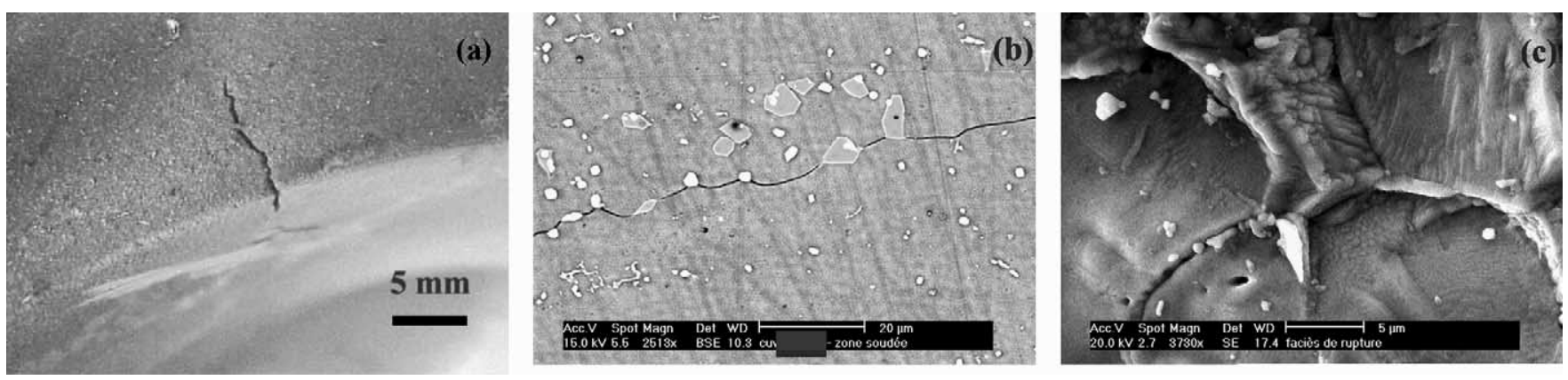

Fig. 2. Damaged industrial dies showing crack on a salient edge (a), propagation of a crack along carbides (b), fatigue striation within a welded zone (c).

tion generally occurs within the material according to specific routes, along the eutectic carbides aligned in the direction of the thermal gradient imposed by the cooling consecutive to welding (Fig. 2b). As indicated in Fig. 2c showing typical striation, the propagation of crack is unambiguously due to fatigue consistently with the SPF loading conditions.

\subsection{Microstructure of the weld beads}

The weld beads, deposited using our automated TIG facility, were investigated using non-destructive testing to address their metallurgical quality and check for the possible occurrence of defects with too high density or size, non-suitable for a proper use. Further analysis performed using complementary techniques such as SEM, EDS and microhardness measurements reveals the structural difference between the base alloy and the welded zone.

Fig 3a shows a series of Vickers microhardness indents from the welded joint to the base material across the interface in the case of the high carbon alloy. Note that hardness shows different profile depending on the indented zone. In the weld joint, hardness is nearly constant, around HV280. Conversely, in the base alloy, hardness measurements are much more scattered, including a base line averaging around HV230 and several peaks ranging from HV350 to HV850. The estimation of the thickness of the interfacial zone is approached using zig-zag Vickers indentation in the area as shown in Fig. 3b. Indeed, taking into the relative dimensions

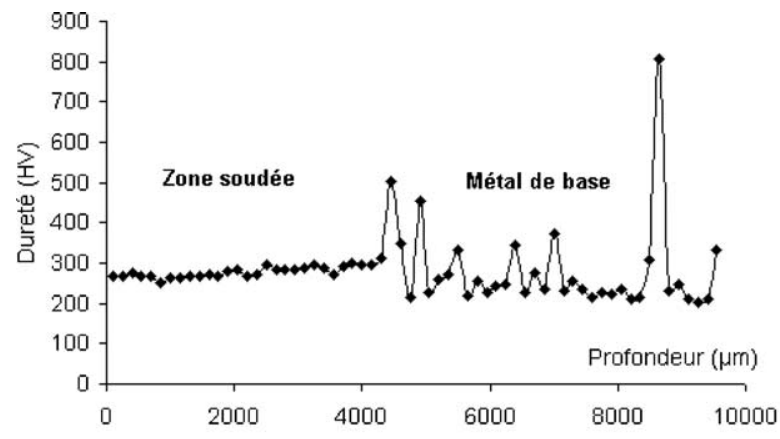

(a) of the indent and the interfacial zone, a straight series of indentation only allows the discrimination between the weld bead and the base metal as shown in Fig. 3a. By shifting the Vickers pyramids between two successive indents, it is possible to estimate the thickness of the zone with rather good accuracy as indicated in Fig. 4a. In such graph, the centre region, about $50 \mu \mathrm{m}$ wide, corresponds to the perturbed zone located between the base metal and the weld bead.

Fig. 4b shows the microstructure of the weld-repaired material: the bottom and the top of the micrograph corresponds respectively to the base metal and welded zone. The two zones are separated by a carbide rich interface. The SEM micrograph confirms the width of this interface, about $50 \mu \mathrm{m}$, estimated using Vickers indentation. The microstructures of the different zones are very similar, regarding the nature of the phases in presence. Indeed, note in each case the presence of an austenitic matrix $\gamma$ along with primary eutectic chromium carbides precipitated between the dendrite arms. However, the morphology of those phases largely varies from one zone to the other. In the base metal, the grain size is about $200 \mu \mathrm{m}$ and the projection in the plane of observation of the dendrite arms is nearly isotropic. This is also clearly visible on SEM micrographs in Fig. 1. Conversely, in the welded zone, the primary carbides are highly elongated in the direction of the thermal gradient established during the solidification. They are also much more finely distributed within the $\gamma$ matrix as shown in Fig. 4b. Eventually, the interfacial zone appears to be a region of preferen-

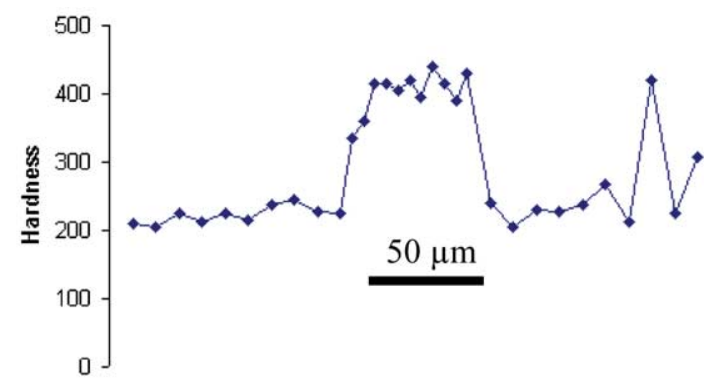

(b)

Fig. 3. High carbon alloy: (a) HV200 g microhardness measurement across the interface between the base alloy and the welded joint; (b) zig-zag microhardness showing the interface width. 


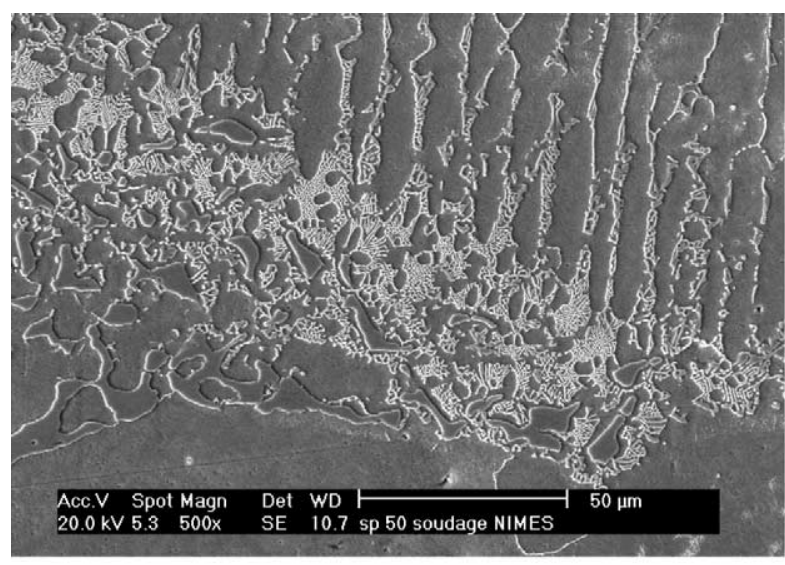

(a)

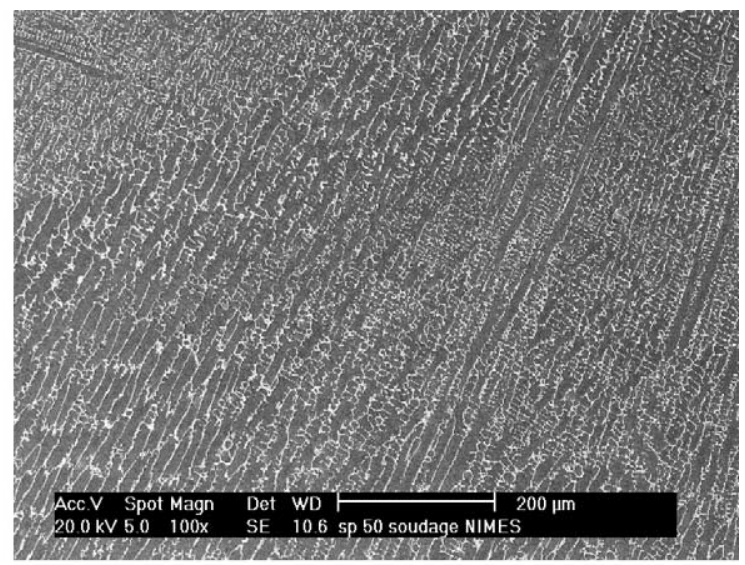

(b)

Fig. 4. High carbon material, SEM micrographs showing the interfacial zone between the metal and the weld bead (a) and the detail of the carbide precipitation in the weld bead (b).

tial carbide coalescence. Those differences are well correlated to the differences revealed by the microhardness profiles discussed above indicating some heterogeneity between the welded zone (indent in regions containing both primary carbides and matrix), the base alloy (indent either in matrix or carbides) and the interface (indent mainly on carbides).

In our case where the filler metal is different from the base alloy, those microstructural differences comes along with differences in both chemical composition and coefficient of thermal expansion which further enhances the heterogeneity. This makes the interface, the zone most likely to damage during service.

Generally speaking, welding of thin plates with a low number of passes gives good results in term of weld bead quality. In this case, the thermal stresses created in the metal during welding may provoke huge bending of the entire plate as thickness is too low to block the deformation. For thicker plates, requiring beyond 10 passes, crack formation and propagation may be observed. In the case shown in Fig. 5, corresponding to the welding of the high carbon material with 47 successive passes, a crack initiated in the carbide rich interfacial zone when depositing the 10th passes. This crack then propagates from pass to pass along the interface between the bead and the metal (Fig. 5a). Further, the crack deviates from the interfacial zone to the base metal propagating along the highly hard and highly brittle eutectic carbide network (Fig. 5b). The deviation into the metal is due to the cumulative thermal stress induced by the successive welding passes.

For the low carbon material, crack propagation could be avoided as shown in Fig. 6a. The quality of the bead is better as indicated by the satisfactory sticking of both welding passes to each other and weld bead to the base metal. Probably due to the lower carbon content, the interfacial zone is, in this case, slightly different from that characteristic of the high carbon material. Particularly the width of the zone, which is much higher in the case of the low carbon alloy. Though showing a microstructure different from both the base metal and the weld bead as it was also the case for the high carbon alloy, the interface exhibits much less carbide

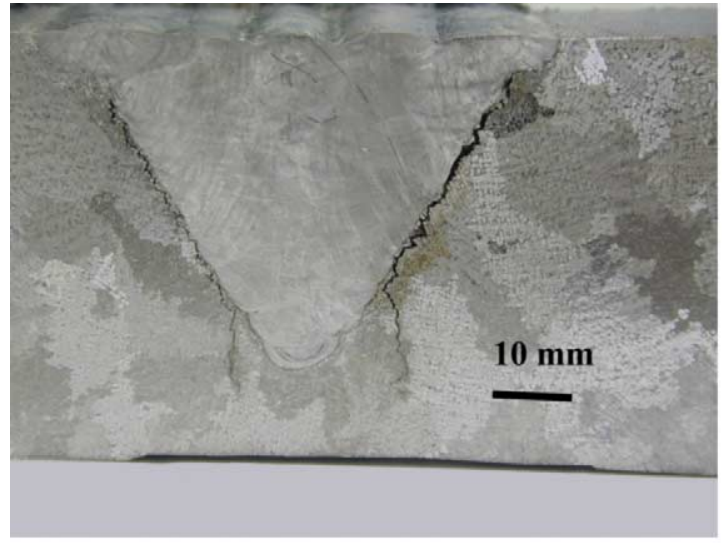

(a)

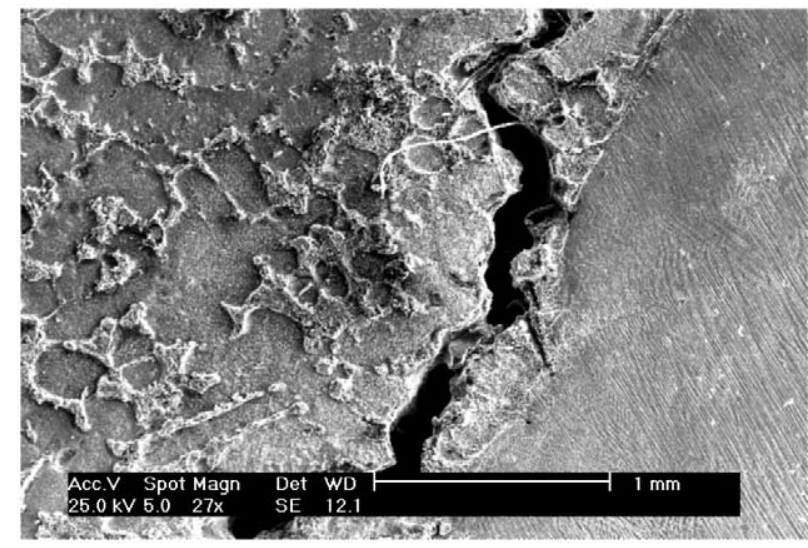

(b)

Fig. 5. High carbon alloy weld-repaired with Inco625: (a) macrograph of the weld bead with interfacial crack; (b) SEM micrograph showing the direction of propagation of the crack. 


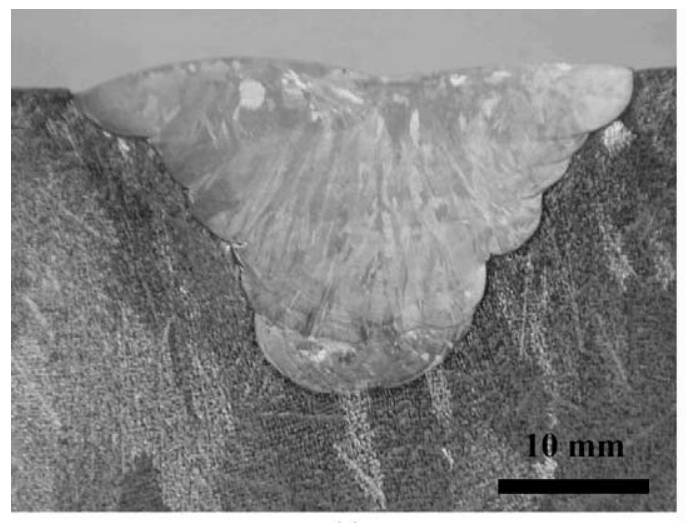

(a)

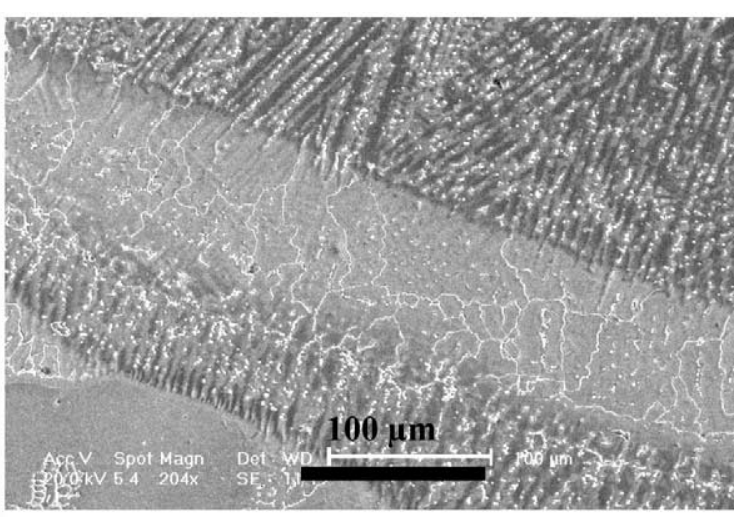

(b)

Fig. 6. Low carbon alloy weld-repaired with Inco625: (a) macrograph of the weld bead; (b) SEM micrograph showing the interfacial zone between the weld bead and the metal.

concentration. As a consequence the interface is likely to show lower brittleness. The interface may accommodate the stress due to the successive welding passes and thus resist better to thermomechanical loading.

\section{Numerical simulation}

The 3D numerical simulation of arc welding problems is complex and generally requires very long computation times. The thermal distribution being a quasi-stationary problem $[2,4,5]$ (i.e. the thermal distribution does not change in a local reference associated to the heat source), excepted near the border of the welded plates, 2D calculations are often preferred.
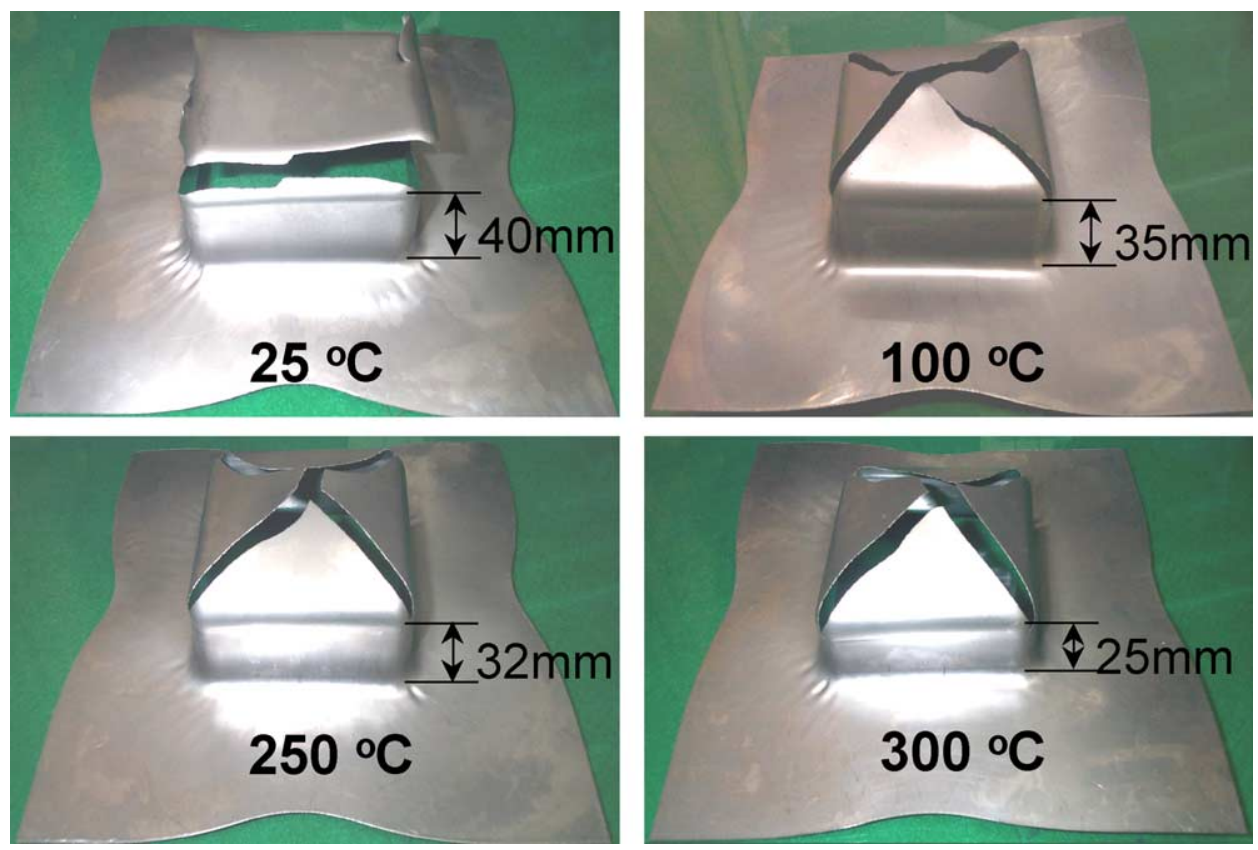

Fig. 7. Thermal properties versus temperature (a) and mechanical behaviour of the base material (b).
The heat-source distribution is given by the model developed by Goldak et al. [2], often called double ellipsoidal heat source [4], which defines a volumic distribution of heat flux $q$ in each point of coordinates $(x, y, z)$ :

$$
\begin{aligned}
q(x, y, z)= & Q_{\mathrm{m}} \exp \left(\frac{-\left(x-x_{\mathrm{c}}\right)^{2}}{A^{2}}\right) \exp \left(\frac{-\left(y-y_{\mathrm{c}}\right)^{2}}{B^{2}}\right) \\
& \times \exp \left(\frac{-\left(z-z_{\mathrm{c}}\right)^{2}}{C^{2}}\right)
\end{aligned}
$$

where $Q_{\mathrm{m}}, A, B$ and $C$ are Gaussian parameters and $\left(x_{\mathrm{c}}, y_{\mathrm{c}}, z_{\mathrm{c}}\right)$ are the coordinates of the centre of the heat source. 


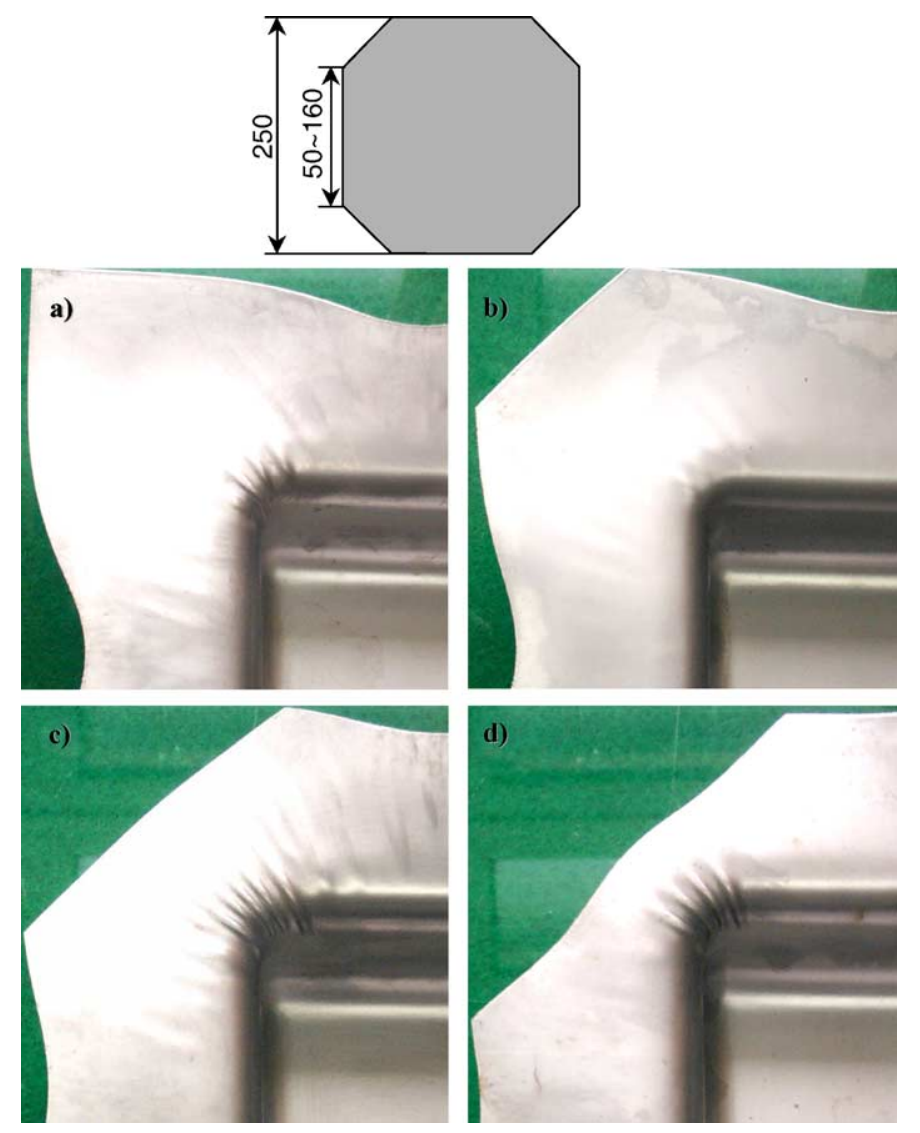

Fig. 8. (a) Double ellipsoidal representation of the heat distribution from the welding arc [2,3]; (b) heat flux in the melt pool; (c) form of the heat intensity on the melt pool.

In a $2 \mathrm{D}$ model, we consider a $(x, y)$ plane which is crossed by the heat source, moving in the $z$-direction at a constant speed $v$. Then, the $z$ coordinate is replaced by $v t$, and Eq. (1) becomes:

$$
\begin{aligned}
q(x, y, t)= & Q_{\mathrm{m}} \exp \left(\frac{-\left(x-x_{\mathrm{c}}\right)^{2}}{A^{2}}\right) \exp \left(\frac{-\left(y-y_{\mathrm{c}}\right)^{2}}{B^{2}}\right) \\
& \times \exp \left(\frac{-\left(v\left(t-t_{\mathrm{c}}\right)\right)^{2}}{C^{2}}\right)
\end{aligned}
$$

\subsection{Thermal boundary conditions}

Convection and radiation heat fluxes are prescribed on the plate surfaces. The prescribed boundary heat convection flux is given by the relation (3):

$q_{\mathrm{c}}=h\left(T-T_{0}\right)$

where $h$ is the convection coefficient $(h=4.5 \times$ $\left.10^{-6} \mathrm{~W} \mathrm{~mm}^{-2}{ }^{\circ} \mathrm{C}^{-1}\right), T$ the temperature of the plate surface, and $T_{0}$ the room temperature.The radiation emission is expressed as:

$q_{\mathrm{r}}=\sigma \varepsilon\left(T^{4}-T_{0}^{4}\right)$

where $\sigma$ is the Stefan-Boltzmann constant $(\sigma=5.67 \times$ $\left.10^{-14} \mathrm{~W} \mathrm{~mm}^{-2}{ }^{\circ} \mathrm{C}^{-1}\right)$, and $\varepsilon$ the surface emissivity $(\varepsilon=$ $0.8)$.

\subsection{Geometry}

The geometric model consists in plates of various thickness (between 18 and $120 \mathrm{~mm}$ ), containing in the centre, a $\mathrm{V}$ groove with 5-7 $\mathrm{mm}$ depth. Each groove is filled in with 2-6 passes of filler metal (multipass welding).

\subsection{Thermal properties}

Thermal properties of the material are given in Fig. 7a. The specific heat, $C_{p}$, increases abruptly at the melting temperature $\left(1450{ }^{\circ} \mathrm{C}\right)$, in order to take into account the heat of transformation.

\subsection{Mechanical properties}

The material presents a standard thermo-elasto-plastic behaviour, with isotropic hardening. The evolution of the yield stress versus the equivalent plastic strain, for different temperatures, is given in Fig. $7 \mathrm{~b}$.

\subsection{Calibration of the heat source}

The double ellipsoidal heat source model needs the determination of four parameters, $Q_{\mathrm{m}}, A, B$ and $C$ (Eq. (2)). The calibration of the heat source consists in fixing these 
parameters to obtain a calculated temperature distribution similar to the distribution measured. Two types of information concerning the temperature distribution, issued from the experiment, are available: the location of the isothermal surface corresponding to the solidus temperature of the material, which delimits the weld pool, and the thermal cycles recorded with thermocouples, in several points around the weld pool.

The calibration of the heat source was performed using the following method:

We assume the heat source is applied to all the volume of the weld pool, which is limited by the surface defined by the following:

$q(x, y, z)=0.05 Q_{\mathrm{m}}$

Then, if we write Eq. (2) in the following form, as proposed by Goldak et al. [2]:

$$
\begin{aligned}
q(x, y, t)= & Q_{\mathrm{m}} \exp \left(\frac{-3\left(x-x_{\mathrm{c}}\right)^{2}}{a^{2}}\right) \exp \left(\frac{-3\left(y-y_{\mathrm{c}}\right)^{2}}{b^{2}}\right) \\
& \times \exp \left(\frac{-3\left(v\left(t-t_{\mathrm{c}}\right)\right)^{2}}{c^{2}}\right) \\
& \text { with } \quad c=c f \text { if } t \leq t_{\mathrm{c}}, c=c b \text { if } t>t_{\mathrm{c}}
\end{aligned}
$$

the parameters $a, b, c f$ and $c b$ correspond to the half axes of the double ellipsoidal surface (Fig. 8a) defined by Eq. (5), and also, according to the previous assumption, to the dimensions of the weld pool, which were experimentally measured.

The first three parameters being fixed, the last one, $Q_{\mathrm{m}}$, is then calibrated to obtain a weld pool surface issued from the simulation (in a transversal plane) similar to the experimentally observed one.

We can see in Fig. 8b, a representation of the heat flux, in the vertical $(x, y)$ plan crossing the centre of the heat source. The maximum heat flux is located at the $x=y=0$ point, which corresponds to the heat source centre location (Fig. 8c). For this representation, $a=2.5$ and $b=2.5$.

This calibration method has been validated by comparing the thermal cycles in different points around the weld pool experimentally measured during welding, and calculated by numerical simulation (for a $18 \mathrm{~mm}$ thick plate with a $\mathrm{V}$ groove of $5 \mathrm{~mm}$ depth). These results, shown in Fig. 9, indicates a rather good agreement between measurements and simulations, and seems to confirm the validity of the calibration method.

\subsection{Results}

In order to explain the cracking phenomenon experimentally observed, results of the numerical simulation and the experiments have been compared. Simulation gives some interesting indications concerning the cracking mechanisms. First, the maximum principal residual stress increases after each pass during multipass welding, except for the sixth pass. Secondly, the location of the maximum principal residual stress is shifted from the bottom to the top of the weld joint (Fig. 10). This is in agreement with the experimental observations, showing crack phenomenon only after about 12 passes, right on the last pass, and not in the bottom of the weld joint. Third, the maximum cumulative plastic strain increases after each pass, and its location also is shifted to the top of the weld joint. This indicates that

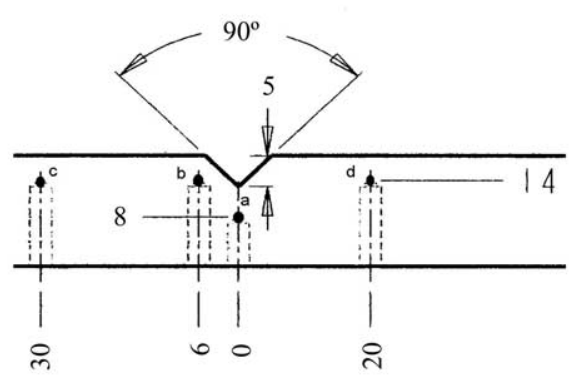

Location of thermocouples $a, b, c, d$ around the V groove
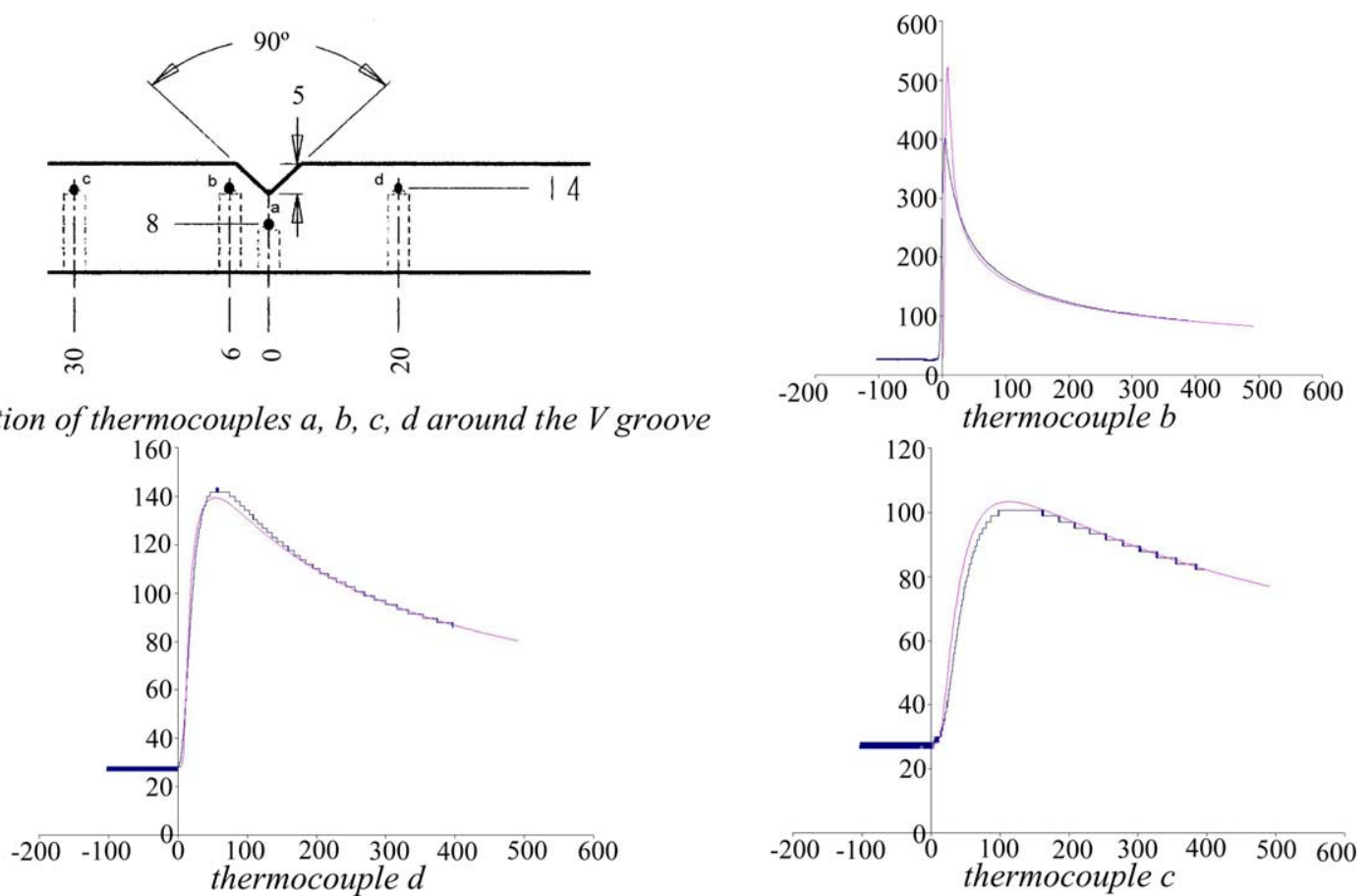

Fig. 9. Comparison between calculated and experimental thermal cycles for different thermocouple locations around the weld pool. 


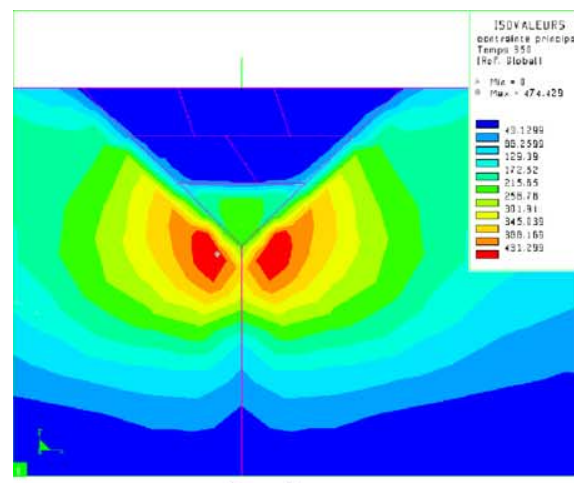

(a) after first pass

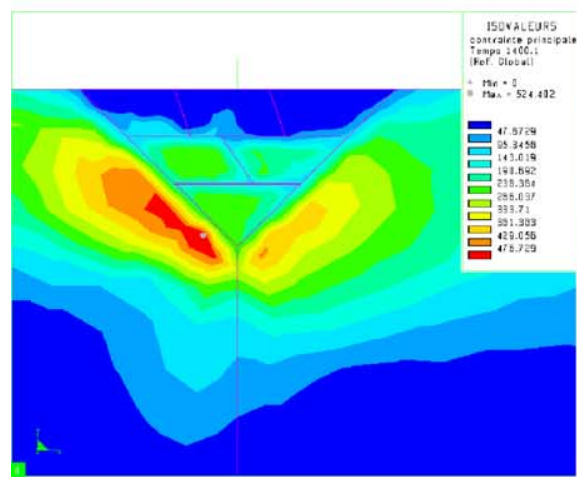

(d) after fourth pass

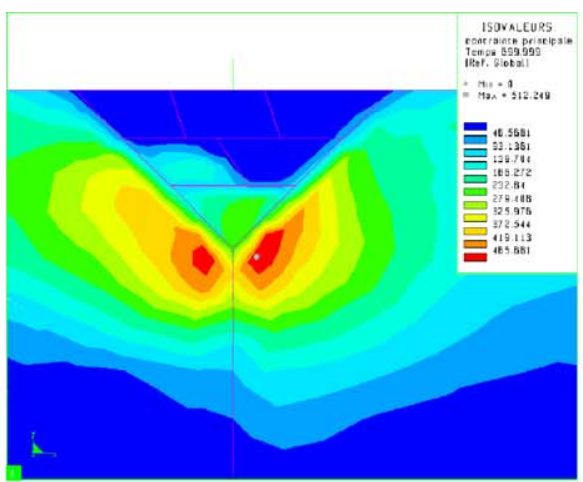

(b) after second pass

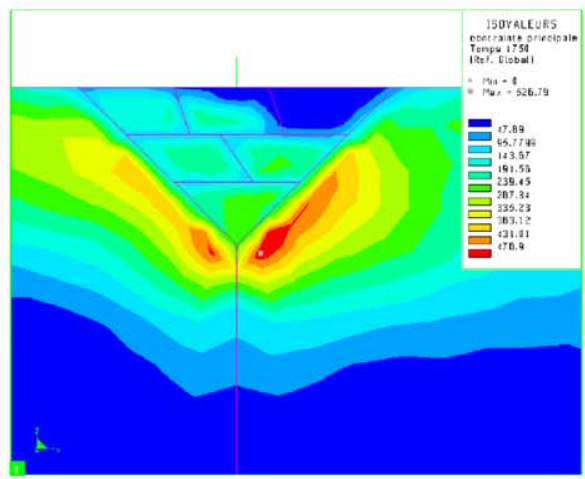

(e) after fifth pass

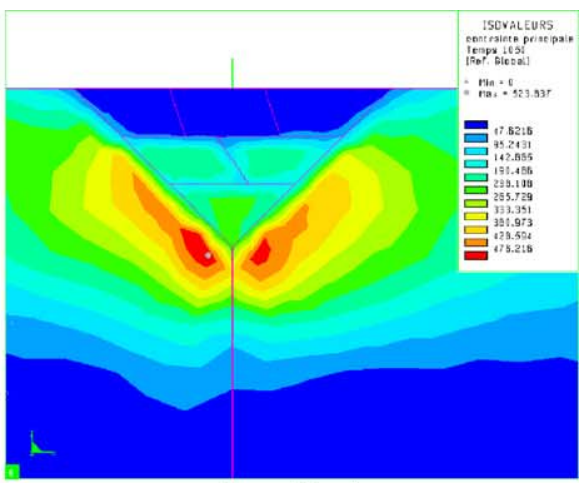

(c) after third pass

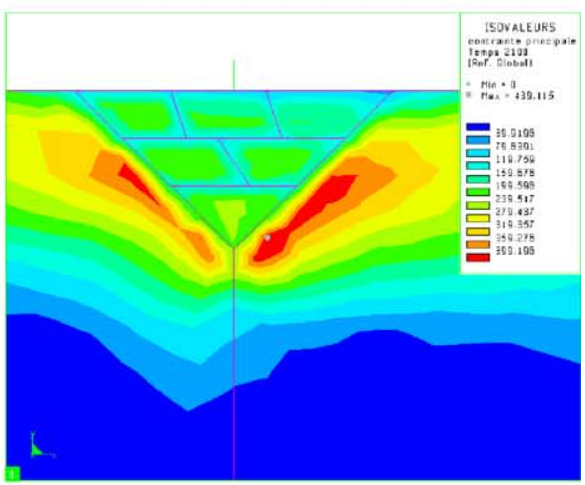

(f) after sixth pass

Fig. 10. Maximal principal stresses after each pass, for a six passes welding.

the multipass welding process has a hardening effect on the base material, and so decreases the ductility of the material. As a consequence, the risk of cracking increases with the accumulation of passes.

\section{Conclusion}

Repairing superplastic forming dies is of primary economical importance as this is the mean to strongly increase life of the tools and thus lower the manufacturing costs drastically. Technically, weld repair, using for instance TIG, remains complex as it must be implemented in hostile industrial environment. As a consequence, it is of utmost concern to perfectly master the welding processes as well as to know and improve the mechanical properties of the welded joints. The work presented in the paper permitted:

- to develop and implement an automated TIG welding equipment for heat resistant cast steels,

- to highlight the microstructural heterogeneity across the interface between the welded zone and the base alloy, mainly related to the morphology of the precipitated primary carbides,

- to address the behaviour difference between low carbon alloy that may be properly weld without cracking and high $\mathrm{C}$ alloy prone to crack upon welding, for which preheat treatment might be necessary,
- to estimate, from local temperature measurements and a two-dimensional numerical simulation approach, the stresses and the strains within the welded plates.

\section{Acknowledgements}

Authors gratefully acknowledge Airbus, Snecma Moteurs, Aubert and Duval et Dassault Aviation for their financial support.

\section{References}

[1] P. Lours, T. Cutard, G. Bernhart, C. Levaillant, Performances of metallic and ceramic tools for superplastique forming, Int. J. Mater. Prod. Technol., SPM1 2 (2001) 445-452.

[2] J. Goldak, A. Chakravarti, M. Bibby, A new finite element model for welding heat sources, Metall. Trans. B 15 (2) (1984) 299-305.

[3] M.H. Davis, M.J. Painter, M. Wahab, A comparison of weld pool shapes predicted form models incorporation conduction and convection, in: Proceedings of the 42nd Annual Conference, Melbourne, October 1994, p. 27.

[4] P.N. Sabapathy, M.J. Painter, M. Wahab, Numerical models of in-service welding of gas pipelines, J. Mater. Process. Technol. 118 (2001) 14-21.

[5] M. Wahab, M.J. Painter, M.H. Davies, The prediction of temperature distribution and weld pool geometry in the gas metal arc welding process, J. Mater. Process. Technol. 77 (1998) 233-239. 